\title{
The Dynamics of Shock Dispersion and Interactions in Supersonic Freestreams with Counterflowing Jets
}

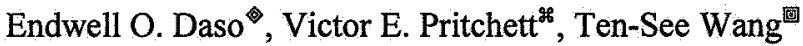 \\ NASA Marshall Space Flight Center, MSFC, AL 35812, USA \\ Dale K. Ota ${ }^{+}$ \\ HyPerComp, Inc., Westlake Village, CA 91362, USA \\ Isaiah M. Blankson* \\ NASA Glenn Research Center, \\ Cleveland, OH 44135, USA \\ and \\ Aaron H. Auslender \\ NASA Langley Research Center \\ Hampton, VA 23681-2199, USA
}

\begin{abstract}
An active flow control concept using counterflowing jets to significantly modify the external flowfields and strongly weaken or disperse the shock-waves of supersonic and hypersonic vehicles to reduce the aerothermal loads and wave drag was investigated. Experiments were conducted in a trisonic blow-down wind-tunnel, complemented by pre-test computational fluid dynamics (CFD) analysis of a $2.6 \%$ scale model of Apollo capsule, with and without counterflowing jets, in Mach 3.48 and 4.0 freestreams, to assess the potential aerothermal and aerodynamic benefits of this concept. The model was instrumented with heat flux gauges, thermocouples and pressure taps, and employed five counterflowing jet nozzles (three sonic and other two supersonic with design Mach numbers of 2.44 and 2.94) and nozzle exit diameters ranging from 0.25 to $0.5 \mathrm{inch}$. Schlieren data show that at low jet flow rates of 0.05 and $0.1 \mathrm{lb} / \mathrm{sec}$, the interactions result in a long penetration mode (LPM) jet, while the short penetration mode (SPM) jet is observed at flow rates greater than $0.11 \mathrm{~b}_{\mathrm{m}} / \mathrm{sec}$., consistent with the pre-test CFD predictions. For the LPM, the jet appears to be nearly fully-expanded, resulting in a very unsteady and oscillatory flow structure in which the bow shock becomes highly dispersed such that it is no longer discernable. Higher speed camera Schlieren data reveal the shock to be dispersed into striations of compression waves, which suddenly coalesce to a weaker bow shock with a larger standoff distance as the flow rate reached a critical value. The pronounced shock dispersion could significantly impact the aerodynamic performance (L/D) and heat flux reduction of spacecraft in atmospheric entry and re-entry, and could also attenuate the entropy layer in hypersonic blunt body flows. For heat transfer, the results show significant reduction in heat flux, even giving negative heat flux for some of the SPM interactions, indicating that the flow wetting the model is cooling, instead of heating the model, which could significantly impact the requirements and design of thermal protection system. These findings strongly suggest that the application of counterflowing jets as active flow control could have strong impact on supersonic and hypersonic vehicle design and performance.
\end{abstract}

\section{Introduction}

One of the technical challenges in space exploration and interplanetary missions is controlled entry and re-entry into planetary and Earth atmospheres, which requires the dissipation of considerable kinetic energy as the spacecraft decelerates and penetrates the atmosphere. As such, effective heat load management of stagnation points and acreage heating remain a technological challenge and pose significant risk, especially for human missions.

\footnotetext{
$\diamond$ AST, Aerospace Flight Systems, Senior Member, AIAA, E-mail: Endwell.O.Daso@nasa.gov

H AST, Aerospace Engineer, Member, AIAA

回 Technical Assistant, Senior Member, AIAA

$\downarrow$ Member of Technical Staff, Senior Member, AIAA

* Senior Technologist, Associate Fellow, AIAA

(1) Assistant Head, Hypersonic Airbreathing Propulsion Branch
}

This paper is declared a work of the U.S. Government and is not subject to copyright protection in the United States. 
The efficiency and performance of an aerospace vehicle or spacecraft in atmospheric flight are dictated by the physics of the flowfield about the vehicle. Flowfields of supersonic and hypersonic vehicles are characterized by strong shock waves, contributing disproportionately to the vehicle drag and aerothermal loads, which translate into poor aerodynamic performance (lift/drag) and stringent thermal protection system (TPS) requirements, and other performance penalties including vehicle range, weight and payload.

In this work, we start out with an extensive review of previous work in counterflowing or opposing jets for vehicle drag and heat flux reductions in supersonic and hypersonic flows. This is followed with the discussion of the results of the experimental and computational analyses we performed to gain a better understanding of the flow physics in order to advance the technology readiness level of the application of counterflowing jets as a viable active flow technology, and demonstrate the effects and potential benefits of the concept.

\section{Background}

Since the early 1950 s there has been continued interest in the application of "active flow control" concepts to modify or change the external flowfields of transonic, supersonic and hypersonic vehicles and spacecraft in order to reduce wave drag and aerothermal loads, and for spacecraft deceleration. Thus active flow concepts to weaken the shock systems received considerable interest in the $1950 \mathrm{~s}^{1-6}$. The work of Stadler and Inouye ${ }^{2}$ showed that opposing jets at low "flow weights" or flow rates doubled the convective heat transfer to a hemispherical model while the heat transfer was reduced by half with tangentially injected jets at equivalent flow weights at the stagnation point. On the other hand, the results of Rashis ${ }^{3}$ showed considerable surface cooling with counterflowing water jets. Ferri and Bloom ${ }^{4}$ conducted analysis, based on an approximate theory, and tests of upstream water and air injection in a Mach 6.1 freestream with five model shapes, from a sphere-cylinder to cone-cylinders with slightly different heights. Their study showed that directed upstream fluid injection could be effective means of cooling in hypersonic flow and the theoretical analysis correlated well with the air jet cooling on the $50^{\circ}$ cone model. Resler and Sears explored the use of electromagnetic effects to improve aerodynamic performance and Ziemer ${ }^{6}$ demonstrated the effects of magnetic fields on the standoff distance of the bow shock of a sphere in a supersonic stream, at the same time showing the bow shock to be significantly diffused, with an attendant increase in shock standoff distance.

Studies were also done on various flowfield modifications for wave drag and heat load reduction, and also as potential improvements for radio wave attenuation as a solution for communications blackout, in the 1960s and $1970 \mathrm{~s}^{7-18}$, using both gas and liquid counterflow or forward-facing jets, including a flight test experiment ${ }^{11}$. Warren ${ }^{7}$ conducted an experimental study of the effect of ejecting nitrogen and helium gases upstream into a Mach 5.8 freestream of a sphere-cone model. The coolant gases effectively reduced the heat flux on the model if the freestream was not disturbed by the injected gas, that is, at low coolant gas flow rates, while the coolant effectiveness was considerably reduced at larger flow rates. He also noted that with the injection, a "stagnation circle" formed on the model with an attendant increase in the heat flux, resulting in a net heat flux greater than the case without any injection.

Charczenco and Hennessey ${ }^{8}$ employed a retrorocket to produce a supersonic counterflowing jet to investigate drag reduction on a sphere with a conical aftbody model. They observed flow instability about the nose, and the drag was reduced below the case with the retrorocket off except at very large retrorocket thrust coefficients. Romeo and Sterrett ${ }^{9,12}$ investigated the effect of a forward-facing jet on the bow shock of blunt body in a Mach 6 freestream. Their investigation revealed two modes of shock displacement: one in which the blunt body bow shock grew in size but retained its structure, while in the second mode, the shock standoff distance increased considerably with the shock becoming less steady with increasing Mach number and high total pressure ratios. Grimaud, and McRee ${ }^{10}$ performed stagnation-point gas injection experiment on a hemispherical-cone in a hypersonic arc tunnel. At lower coolant flow rates, the blunt body heating rates increased initially, but decreased with increasing flow rate, with up to a $33 \%$ reduction in heat transfer for different coolants at the maximum coolant injection rates. Beckwith and Bushnell ${ }^{11}$ reported the results of the flight test experiment at $150,000 \mathrm{ft}$. altitude and a velocity of $14,000 \mathrm{ft} / \mathrm{s}$, using intermittent nose and side port water injections to reduce aerodynamic heating of a sphere-cone with $9^{\circ}$ half-angle cone-cylinder flare and a spherical blunt nose (RAM B2). They reported a decrease in surface temperature ranging from $155^{\circ} \mathrm{F}$ to $408^{\circ} \mathrm{F}$, corresponding to heat loads of 240 to $470 \mathrm{Btu} / \mathrm{ft}^{2}$ over a period of 90 seconds due to the water injection. From their data and water evaporation theory, they calculated negative surface heat transfer, indicating the cooling effect of the pulsed side port injection, which progressively became less negative with distance from the port.

Barber ${ }^{13}$ tested the cooling effects of counterflowing stagnation point injection with nitrogen, helium and hydrogen on a $90^{\circ}$ sector copper hemisphere in a Mach 6-8 tunnel with total enthalpies between 1500 to 5000 $\mathrm{Btu} / \mathrm{lb} \mathrm{m}$. For nitrogen and helium injections, the average heat transfer decreased initially with increasing "relative mass flow," while it increased by $10 \%$ above the no injection case due to an impinging or reattached "stagnation 
ring" at a "relative mass flow" of about 8 . For hydrogen injection, they reported a $65 \%$ increase was found as a result of combustion. However, as the relative mass flow increased, the average heat transfer decreased considerably, becoming as low as $10 \%$ of the case with no injection at large relative mass flows for all test gases. Finley ${ }^{14}$ analytically and experimentally investigated counterflowing jets in a Mach 2.5 freestream using two jet nozzles: a sonic and a Mach 2.6 nozzle, having different diameter ratios with respect to the model. His detailed analysis showed that the effects of the jet Mach number and "flow force coefficient," are critical in determining whether the flow is steady or unsteady. Keyes and Hefner ${ }^{15}$ conducted tests with "retro-propulsion" as counterflowing jets for spacecraft deceleration in atmospheric decent and showed that for jets located at the periphery, the aerodynamic drag generally increased with jet total pressure.

Bushnell and Huffman ${ }^{16}$ studied long penetration jet interactions and noted that the cooling effects of stagnation point injection depended on the penetration distance of the water jet. Jarvinen and Adams ${ }^{17}$ showed that for single nozzle retrorocket engine on conical aeroshell planetary entry vehicles, the flowfield had two regimes of jet penetration; long penetration at low "thrusting" coefficients and a short blunt jet penetration which terminated in a terminal shock ${ }^{14}$ at large coefficients. They also observed that the transition from long penetration to short penetration occurred at fixed jet exit pressure to freestream pressure ratio for all engine sizes tested. McGhee ${ }^{18}$ also investigated the effects of centrally located "retronozzle," with an exit Mach number of 3.0 , on a $140^{\circ}$ blunt cone in Mach 3.0, 4.5 and 6.0 freestreams at $0^{\circ}, 2^{\circ}$ and $5^{\circ}$ angles of attack. From the observations of the flow physics, three regimes were identified in terms of the nozzle jet expansion: Regime 1, where the jet was over-expanded with the local flow static pressure greater than the jet exit pressure; Regime 2, where the jet was fully-expanded with the local flow static pressure approximately equal to the jet exit pressure, and Regime 3, where the jet was under-expanded, with the local flow static pressure less than the jet exit pressure. For Regimes 1 and 2, the flowfield was unsteady, while it was steady in Regime 3 at all angles of attack. In the steady flow regime, locations of the jet (barrel) shock, flow interface and the bow shock were found to be primarily a function of nozzle thrust coefficient. Grenich and Woods ${ }^{19}$ demonstrated the concept for heat load and drag reduction on ballutes in a Mach 20 freestream, and also identified regions of steady and unsteady flow for low and high jet flow rates ${ }^{18}$, respectively. Their test results show significant reduction in the drag coefficient on the ballute as a function of jet flow rate.

In recent years, there has been a strong interest in the application of weakly ionized nonequilibrium plasma (WINP) counterflowing jets for the reduction of wave drag and heat flux of bodies in supersonic and hypersonic flows. More recent work ${ }^{20-40}$ have revealed that WINP jets into high-speed flows produce various shock-attenuating and anomalous effects. Malmuth et al. $^{34}$ and Formin, et al. ${ }^{35}$ studied different jet penetrations in plasma jet experiments with truncated cone-cylinder models in Mach 2, 2.5, and 4 supersonic freestreams. These experiments also revealed two modes of jet-penetration: short penetration mode (SPM) and long penetration mode (LPM), consistent with the previous findings of Refs. 17 and 18, with the LPM giving greater reduction in wave drag and larger shock stand-off distance.

Shang, et al. ${ }^{36-38}$ and Shang ${ }^{39}$ have investigated experimentally and computationally the aerodynamic effects of various counterflowing jets, with and without plasma, to determine the amount of drag reduction in a hypersonic flow over a sphere. The jet penetration was observed to have two stability modes: an unsteady oscillatory motion under a "subcritical" state and a nearly steady "supercritical" state beyond the shock bifurcation point, depending on the driving stagnation pressure and mass flow rate of the jet. The drag reduction was found to depend strongly on the jet mass flow rate, in agreement with previous work, and had the same trend with and without the plasma. However, the plasma jet gave about $10 \%$ more reduction in $\mathrm{drag}^{39}$ which was attributed to the deposited thermal energy of the plasma. Josyula et al. ${ }^{40}$ investigated the applications of counterflowing jets for drag reduction in high speed systems, and came to the conclusion that it is most suited for hypersonic blunt nosed bodies. Gilinsky, et al. ${ }^{41}$ conducted experiments and CFD analysis to modify the shock wave of cylindrical and "butt-end" blunt bodies in subsonic and supersonic flows using single and multiple needles, and opposing liquid jets. Their results showed a considerable reduction in drag, with the drag coefficient decreasing with flow rate.

Daso, et al. ${ }^{42}$ obtained a CFD solution for the SPM jet giving better than $15 \%$ reduction in drag, accounting for the jet thrust, from a sonic counterflowing jet of a truncated cone-cylinder in a Mach 2 freestream, and also developed an analytical approach to establish a sustained LPM jet. Woods, et al. ${ }^{43}$ showed the effect of counterflowing water jets in a Mach 6 freestream, which significantly modified the strong bow shock on spherecylinder to a oblique shock. Hayashi, et al. ${ }^{44}$ undertook both numerical and experimental study of opposing jets in a supersonic flow over a sphere-cylinder for thermal protection. Similar to previous work, their study also showed considerable reduction both in drag and heat transfer. They also identified both steady regime and unsteady flow with shock oscillations, depending on the ratio of the stagnation pressure of the jet to that of the freestream. 
The above review shows the extensive body of work on the use of counterflowing or opposing jets to modify supersonic and hypersonic flows for shock attenuation, and the reduction of wave drag and heat transfer. However, in nearly all the previous work, the model geometries used were typically sphere-cylinders, sphere-cones, cylinders, (truncated) cone-cylinders or a simple aeroshell. Thus, there is a paucity of work with models that are more representative of actual spacecraft configurations such as re-entry vehicles. In this work, we investigated experimentally and numerically the flow environment of supersonic freestream-counterflowing jet interactions, and the attendant aerodynamic and aerothermal effects of an actual spacecraft model, a $2.6 \%$ scale Apollo capsule. We discuss below the results of the analyses of the flow structure of the Apollo capsule model to gain a better insight of the flow physics to advance the technology readiness of active flow control as a viable technology for spacecraft, and supersonic and hypersonic vehicles for mitigating aerothermal loads and improving lift to drag ratio for enhanced aerodynamic performance. Though the review of previous work above included counterflowing plasma jets in order to discuss a broader body of work, the work reported here does not include weakly ionized plasmas jets or any plasma effects. Thus, only "cold" counterflowing jets were employed in this study.

\section{Model Geometry and Instrumentation Description}

The test model is a $2.6 \%$ scale Apollo capsule of 4 " diameter, designed to accommodate five axisymmetric interchangeable counterflowing jet nozzles, as shown in Fig. 1. The secondary air supply feedline to the nozzles is housed in the model sting (Fig. 1c). The feedline is a 5/8" OD high pressure tube welded to the backside of the nozzle socket and regulated with a maximum of $900 \mathrm{psi}$ valve. A Schlieren flow visualization system with low and high speed cameras was also used to visualize the flowfield and capture the interactions and resulting shock structure and dynamics. Pressure, heat flux and temperature data were acquired with a newly installed Labview data acquisition system. The instrumentation consists of 56 static pressure ports and 15 Medtherm Schmidt-Boelter heat flux transducers/thermocouples (model no. 8-5-0.5-36-SE-20486, range: 0-5Btu/ $\mathrm{ft}^{2} \mathrm{sec}$, with calibration uncertainty of $\pm 3 \%$ responsivity) on both the heatshield and the conical aftbody, which is truncated slightly to admit the specially designed sting. The gauges were installed in a circular pattern or rows, with each row having three or more gauges, Fig. 1c. The model and the nozzles are made with 174 PH H1050 stainless steel. The nozzles are trapped in a bore in the base and are held in place by jack-on screws. The design allows the nozzles to be readily replaced or interchanged with another from the heatshield side or face of the model without the need for disassembly or the removal of the model from the sting during testing. Figure 2 shows the three sonic and two Mach 2.44 and 2.94 supersonic nozzles. The blank was used for the baseline geometry (no injection). The diameters of the nozzle exits vary from 0.25 " to 0.5 " to assess the effective of nozzle geometry. The nozzle countours were designed using an inhouse nozzle design code, $\mathrm{ADAPT}^{45}$, which uses the method of characteristics with boundary layer displacement thickness correction.

\section{Facility Description}

The test facility used for the experiments is the Marshall Space Flight Centers (MSFC) trisonic wind tunnel (TWT). The test section of the tunnel has a 14"X14" cross-section and is 21 " long. It is an intermittent blow-down tunnel, which operates by high-pressure air flowing from storage tanks to atmospheric or vacuum conditions. The test section provides Mach numbers ranging from 0.2 to 4.96. Mach numbers between 0.2 and 1.3 are obtained by using a variable diffuser, while the transonic Mach numbers of 0.95 to 1.3 are achieved through the use of plenum suction and perforated walls. A solid wall supersonic test section provides the entire range of Mach numbers from 2.74 to 4.96 , with one set of automatically actuated contour nozzle blocks. A hydraulically controlled pitch sector located downstream of the test section provided the capability of testing at angles-of-attack from $-10^{\circ}$ to $+10^{\circ}$. For the tests performed in this study, the freestream Mach numbers were 3.48 and 4.0 for both the baseline geometry and with counterflowing jet nozzles. At Mach numbers higher than 4.0, the tunnel could not establish uniform flow due to blockage. The tunnel conditions for the Mach 3.48 and 4.0 freestreams were total pressure of 44.92 psi and 54.85 psi, total temperature of $581.38^{\circ} \mathrm{R}$, and $575.84^{\circ} \mathrm{R}$, and unit Reynolds no. of $4.88 \times 10^{6}$ and $4.67 \times 10^{6}$, respectively.

\section{Test Run Matrix}

The run matrix included a wide range of jet parameters and two freestream supersonic Mach numbers of 3.48 and 4.0. There were five counterflowjet nozzles: three sonic and two supersonic, with varying nozzle exit diameters of 0.25 ", 0.375 " and 0.5 " to determine the effect of the nozzle Mach number and geometry. The nozzles were run at design flow rates of $0.05,0.10,0.25,0.35$ and $0.501 \mathrm{~b}_{\mathrm{m}} / \mathrm{sec}$, the corresponding to nozzle stagnation pressure and temperatures are given in Table 1 , as well as at three jet angles of attack of $+5^{\circ}, 0^{\circ}$ and $-9^{\circ}$ to determine the effects of flow rate and the angle of attack on the flow structure and interactions. 

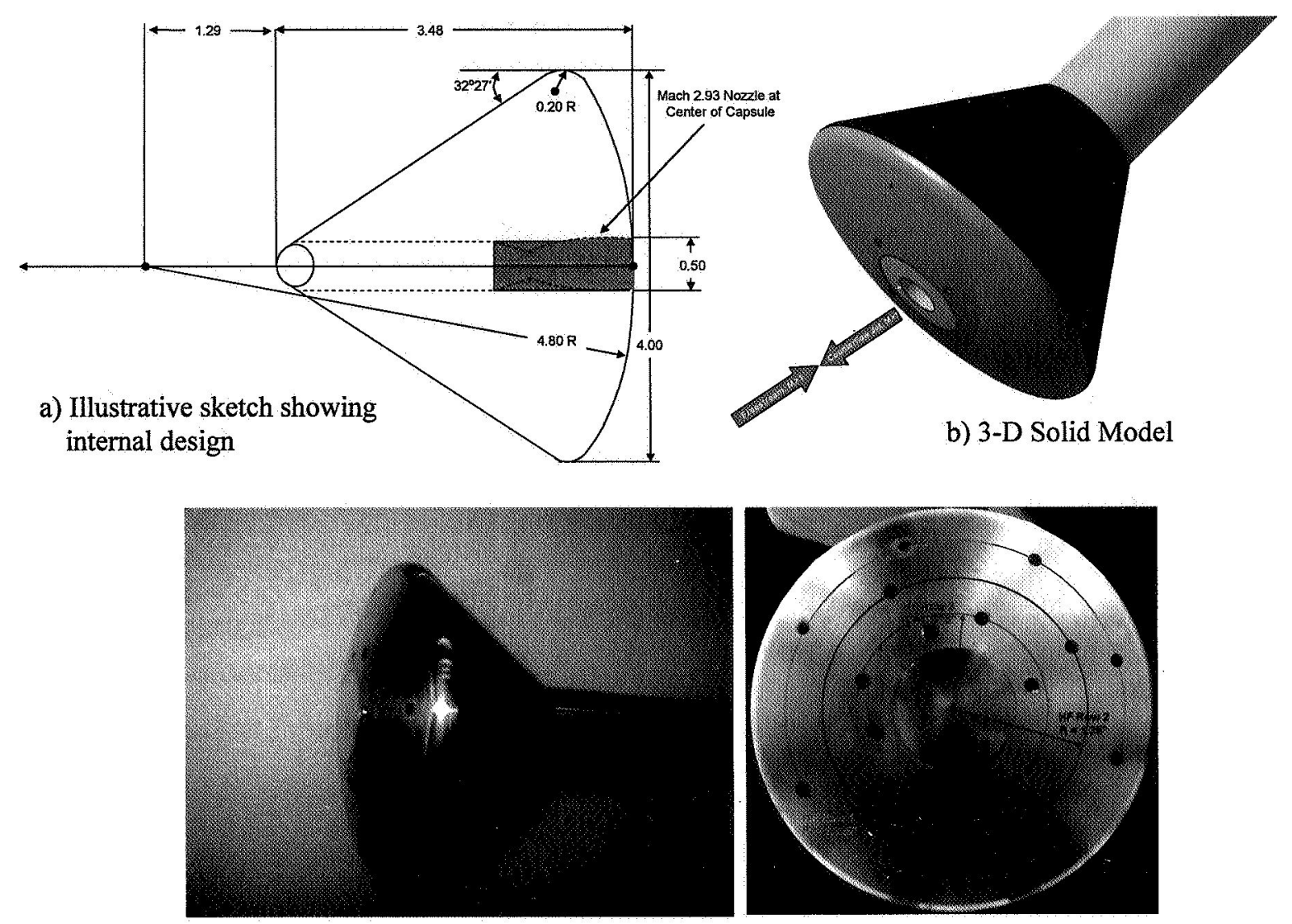

c) Model with heat flux (visible) and pressure tap instrumentation.

Figure 1.2.6\% Scale model of the Apollo capsule

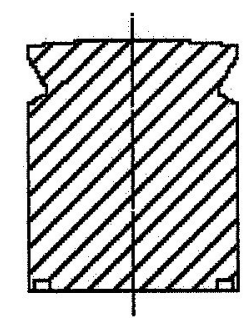

Blank for Baseline

Geometry

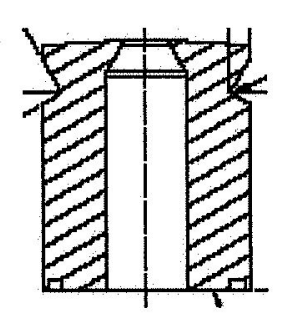

0.25 " $\mathrm{D}_{\text {exit }}$ Sonic Nozzle

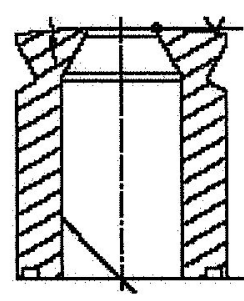

0.375 " $\mathrm{D}_{\text {exit }}$ Sonic Nozzle

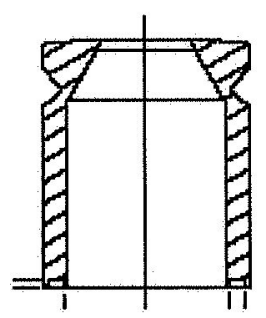

0.5 " $\mathrm{D}_{\text {exit }}$

Sonic Nozzle

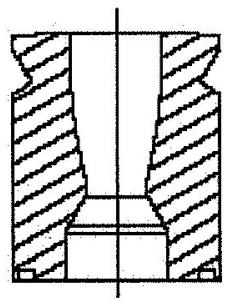

0.5 " $\mathrm{D}_{\text {exit }}$

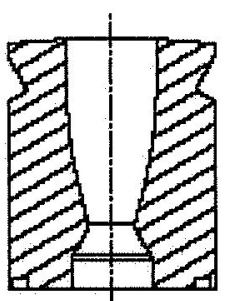

0.5 " $\mathrm{D}_{\text {exit }}$

Mach 2.44 Nozzle Mach 2.94 Nozzle

Figure 2. Sonic and Supersonic counterflowing jet nozzles, and blank for baseline geometry. 


\section{Numerical Simulations}

The numerical simulations discussed below were performed with the HyPerComp, Inc. in-house USA flow solver. The USA code is a 3-dimensional structured-grid Reynolds-averaged Navier-Stokes equations solver, with perfect gas, finite-rate chemistry, equilibrium chemistry and equilibrium air curve fit options, and has been widely used and validated ${ }^{46-48}$. The turbulence model is the pointwise Goldberg one equation turbulence model. The computational grids were generated with HyPerComp's TEMPUS-GRID structured and unstructured grid generator. Figure 3a shows the computational grid with the sting, with about 750,000 points or nodes, to simulate one half of the computational domain, with a plane of symmetry at $z=0$ (center of the computational domain). A grid refinement study was conducted to determine grid independence in heat transfer and to resolve the boundary layers, resulting in a maximum $y^{+}<0.1$. The grid of the flowfield was made of ten zones. The solutions discussed here were obtained with the perfect gas option of the solver and Goldberg's one equation turbulence model.

Figure $3 \mathrm{~b}$ shows the computational grid of the flowfield at the plane of symmetry with the model and sting at a $10^{\circ}$ angle of attack, with about 775,000 nodes and 12 zones. Though the $\mathrm{y}^{+}$was about the same to the grid at $0^{\circ}$ angle of attack, this grid was more refined to better resolve regions of high gradients. This was consistent with the experimental setup where the center point of the nozzle exit does not move and the capsule rotates about that point.

Figure 4 shows the computational grid of one of the supersonic nozzle. The nozzle grids were set up as single zones, and were only included in the computation for the cases with counterflowing jets. About 25,000 grid points were used for the nozzle grid.

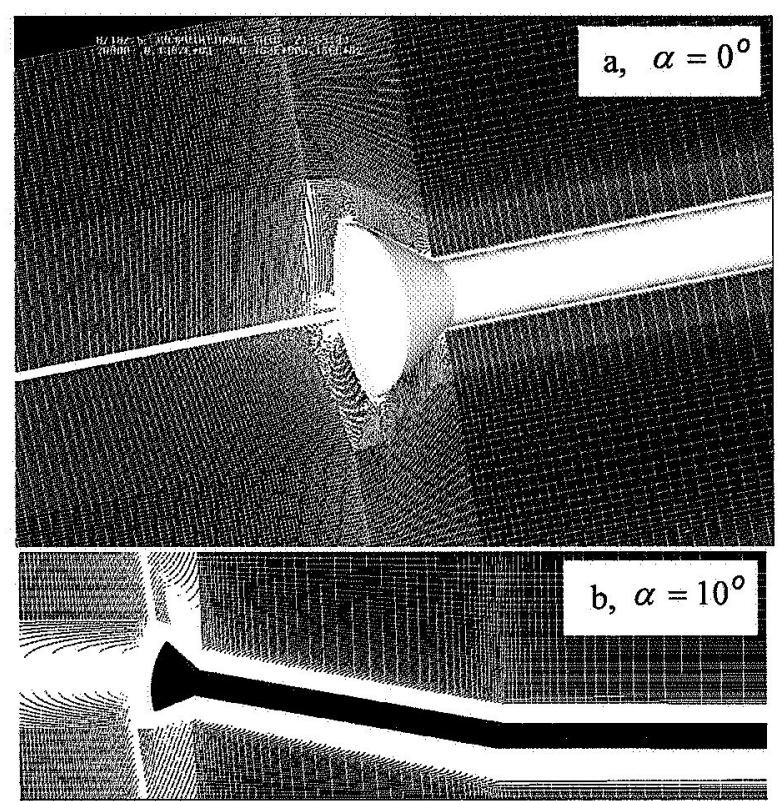

Figure 3. Surface grid at plane of symmetry with sting.

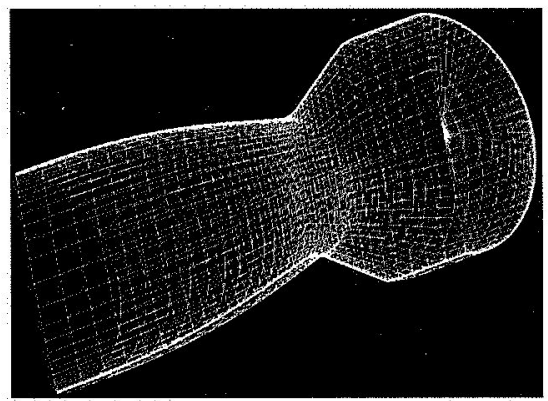

Figure 4. Mach 2.94 nozzle grid with 0.5 " diameter.

\section{Low speed camera Schlieren data}

\section{Results and Discussion}

We start with the discussion of the test results, with a focus on the dynamics of the freestream-counterflowing jet interactions and characteristics of the flow structure. As discussed above, the test matrix included a wide range of parameters: five jet nozzle geometries (with three sonic jet Mach numbers and two supersonic Mach numbers of 2.44 and 2.94), in addition to the baseline geometry, five different flow rates and three angles of attack, resulting in nearly 100 runs. The runs were conducted in two sequences for each freestream. In the first sequence, the flow rate of the counterflowing jet was fixed at a given value. Starting with the lowest flow rate, data was acquired successively for each angle of attack, and then the process repeated for the next flow rate. In the second sequence, for a given run, the flow rate was varied from $\dot{\mathrm{m}}_{\mathrm{j}}=0.05$ to $0.50 \mathrm{lb}_{\mathrm{m}} / \mathrm{sec}$ for each freestream Mach number at $\alpha=0^{\circ}$. In addition, some of these runs were repeated with a higher speed camera in the Shlieren system to capture better details or resolution of the flow structure in the cases in which the bow shock is not discernible. Thus, a significant amount of data was generated. In this paper, we discuss only a representative set of the results, including the effects of the flow rate and jet interaction on the heat transfer and shock standoff distance. A companion paper ${ }^{49}$ will give more quantitative and in-depth discussion on some of the flowfield data, including the calibration of the instrumentation and data acquisition system, as pointed out earlier. 
The Schlieren images of the flowfield of the baseline geometry (Fig. 2) is shown in Figs. $6 a$ and $6 b$ for the Mach 3.48 and 4.0 freestreams, respectively, clearly showing the bow shock upstream of the Apollo model, as is expected. The light and dark shades in the Schlieren image is due to the horizontal orientation of the knife edge. Also, a boundary starting from the rim of the model and terminating on the sting, demarcating a pocket of separated

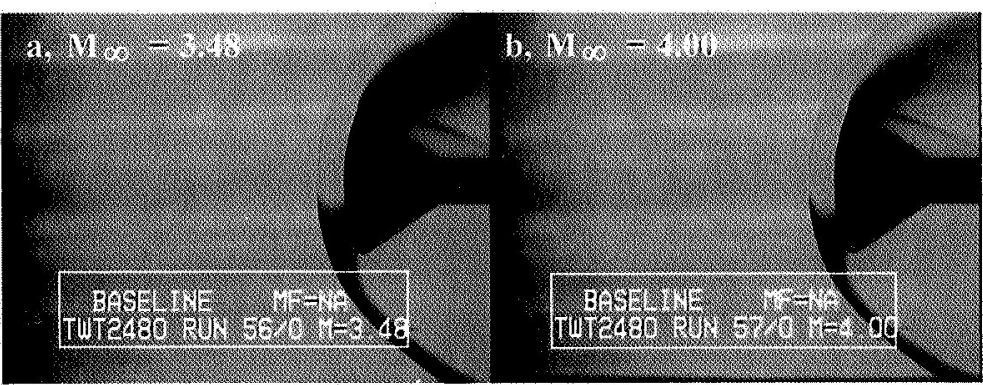

Figure 6. Schlieren images of the flowfield of the baseline geometry - no jet injection. flow on the aft-cone can be readily seen.

The separated flow results from an adverse pressure gradient on the aft-cone due to the expansion fan emanating at the edge of the model, as the flow accelerates at the rim through the Prandtl-Meyer fan.

Figure 7 shows a comparison of the flow structures for the Mach 3.48 freestream and the jet with nozzle exit diameter of $0.5^{\text {" at }} \alpha=0^{\circ}$. The notation "M1-0.5" in the legend denotes the jet nozzle design Mach number and exit diameter. "M1" indicates a nozzle exit Mach number of 1 , while the " -0.5 " is the nozzle exit diameter of 0.5 ". Similarly, in "M2.5-0.5" "M2.5" stands for a design jet Mach number of 2.44, and correspondingly "M3" in "M3.00.5 " is the design jet Mach number of 2.94. "MF" is the flow rate, $\dot{\mathrm{m}}_{\mathrm{j}}$. Figure 7a shows the effect of the flow rate, MF or $\dot{\mathrm{m}}_{\mathrm{j}}=0.0,0.05,0.10,0,0.25,0.35$ and $0.50 \mathrm{lb}_{\mathrm{m}} / \mathrm{sec}$, as noted in the legend. Similarly, Figs. $7 \mathrm{~b}$ and $7 \mathrm{c}$ show the Schlieren images for the flowfields with design jet Mach numbers of 2.44 and 2.94, respectively, for the same jet exit diameter. These Schlieren images show dramatic differences in the flow structure compared to the baseline. In terms of the flow structure, though different regimes have been identified in previous work, two main flow characteristics are evident in the Fig. 7: one in which the counterflowing jet remained essentially a "pencil" of fluid or an aerospike, penetrating far upstream into the oncoming supersonic freestream, known as a long penetration ${ }^{17,35,36}$ mode (LPM) jet; while the other is the short penetration mode (SPM) jet in which the counterflowing jet exhausts into the freestream with the more familiar plume.

As can be seen in Fig. 7, the mode of the jet penetration depends on the flow rate or the driving nozzle stagnation pressure, and therefore the type of nozzle expansion. That is whether the jet is under-expanded, fullyexpanded or over-expanded, based on the pressure difference between the nozzle exit static pressure and the static pressure of the "ambient" or shocked flow. At the low flow rates, $\dot{\mathrm{m}}_{\mathrm{j}}=0.05$ and $0.1 \mathrm{lb} / \mathrm{sec}$, that is the LPM, the counterflowing jet is seen to be "nearly" fully-expanded, with the static pressure of the jet at the nozzle exit being, by definition, (approximately) the same as the static pressure of the "ambient' flow about the nozzle exit, as also noted in the results of Ref. 18. Thus, the LPM jet occurs for both the sonic and supersonic nozzles, with the degree of penetration depending on the jet nozzle exit Mach number, as shown in Figs. 7a, b and c. For the LPM jet flowfield, the flow structure reveals the shock to be so diffused or dispersed that it is no longer discernible, and thus the shock standoff distance can no longer be defined. This degree of shock dispersion is only known to have been observed in the Schlieren images of McGhee ${ }^{18}$, who identified three different flow regimes in the flowfield of a Mach 3 freestream with a $140^{\circ}$ cone having a centrally located Mach 3 "retronozzle" at $\alpha=0^{\circ}$. Such degree of dispersion or dissipation of the bow shock of the model could have important applications in supersonic and hypersonic aerodynamics if it can be sustained.

An equally important characteristic of the flowfields with LPM jets is the rather pronounced unsteadiness of the freestream-counterflowing jet interactions at low jet flow rates, thrust or mass flow coefficients, ${ }^{8,9,14,18,19,36,35,44}$ and oscillation ${ }^{9,44}$ through a feedback mechanism. The feedback mechanism is sustained by the mixed hyperbolic-elliptic character of the flowfield. Though definitive explanation for this self-sustaining unsteadiness has remained elusive, there are two plausible explanations. That is, the unsteadiness and oscillations either result from the transitioning of the nozzle wall laminar boundary layer into turbulent fluctuations ${ }^{9}$ and promoting mixing as the opposing streams interact, particularly in the case of the supersonic nozzles, or from pressure perturbation in "dead-air" regions ${ }^{14}$ of the flowfield. This unsteadiness and oscillations are readily noticeable in the Schlieren videos.

Figure 7 also reveals dramatic changes in the flow structure and dynamics of the interaction as the counterflowing jet flow rate was increased above $\dot{\mathrm{m}}_{\mathrm{j}}=0.10 \mathrm{lb} / \mathrm{sec}$. For $\dot{\mathrm{m}}_{\mathrm{j}} \geq 0.25 \mathrm{lb} / \mathrm{sec}$, it is seen that the flow 

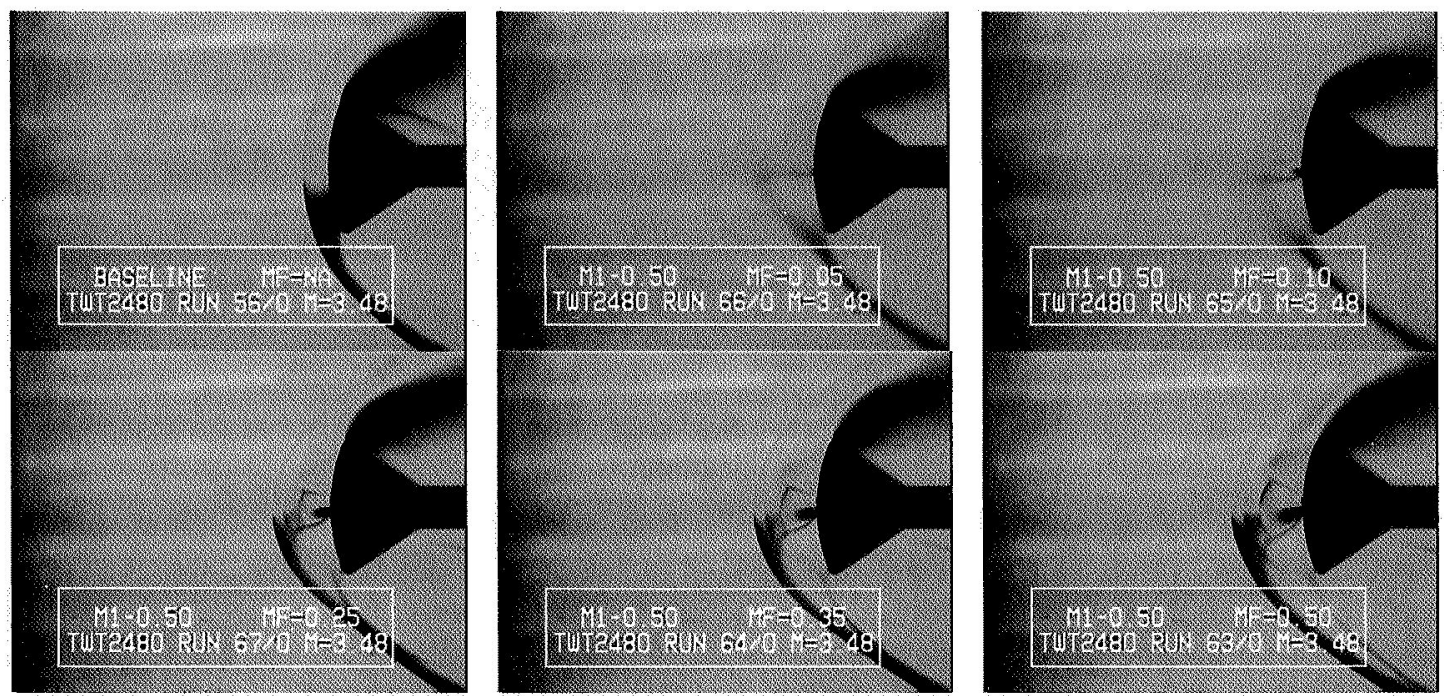

a) Effect of flow rate, $\operatorname{MF}\left(\dot{m}_{j}\right)$ : Jet Mach number is sonic, nozzle exit diameter $=0.5^{\prime \prime}$.
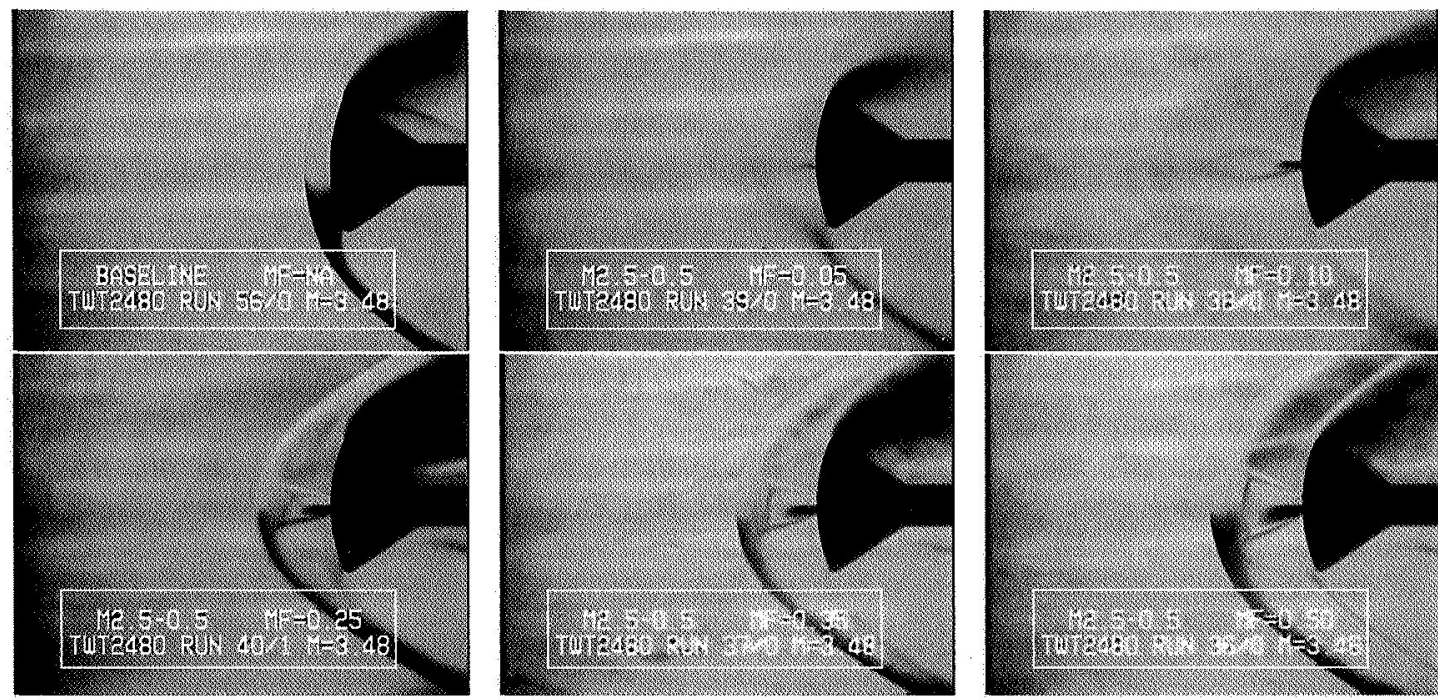

b) Effect of flow rate, $\mathrm{MF}\left(\dot{\mathrm{m}}_{\mathrm{j}}\right)$ : Jet Mach number $=2.44$, nozzle exit diameter $=0.5$ ".
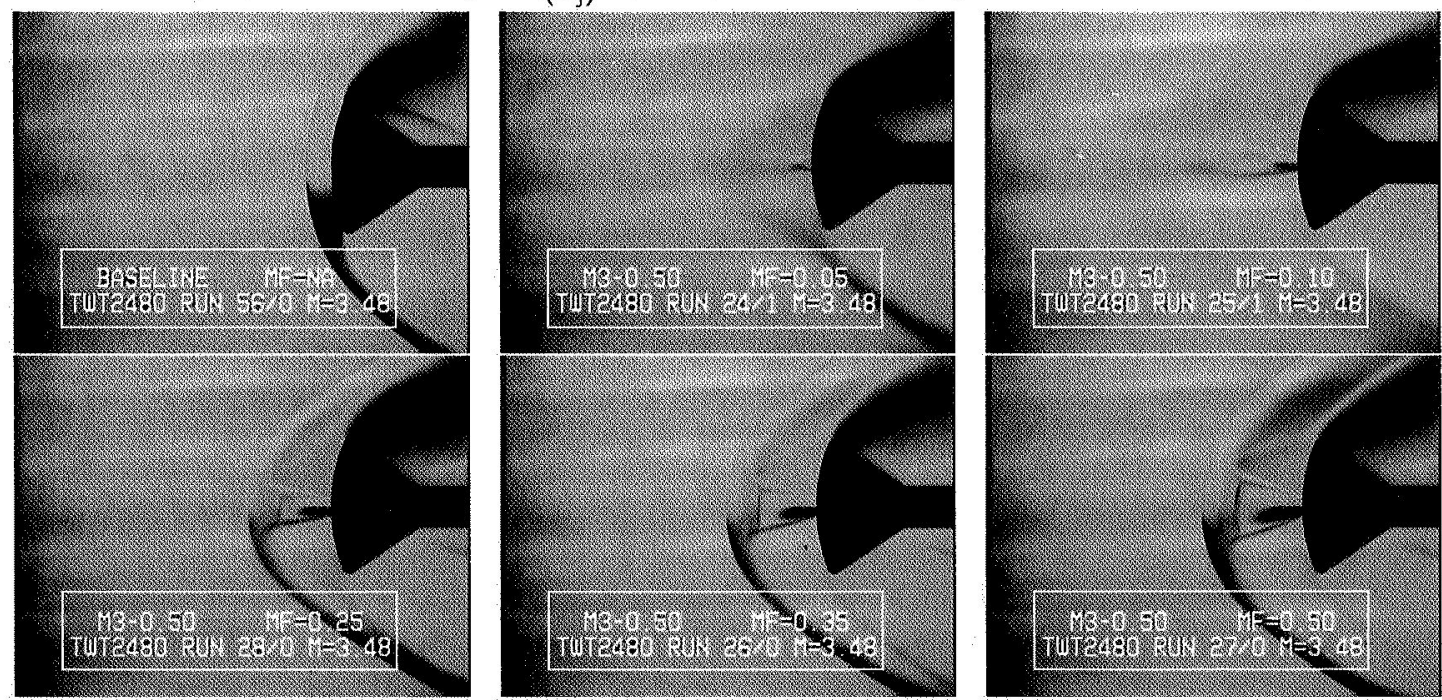

c) Effect of flow rate, $M F\left(\dot{m}_{j}\right)$ : Jet Mach number $=2.94$, nozzle exit diameter $=0.5$ ".

Figure 7. Effects of Mach number and flow rate on the interaction of the counterflowing iet with Mach 3.48 freestream. 
structure has transitioned from the LPM to the SPM. As seen in the Schlieren videos, the transition is sudden or the LPM jet "jumps" to the SPM at a critical flow rate, with a concomitant reduction in the upstream jet penetration to instantaneously reestablish a weaker bow shock with longer standoff distance compared to that of the baseline flow.

In the SPM, the jet is delineated by a barrel shock, capped with a terminal spherical shock downstream of the bow shock, and with an interface located about midway from either shock. At the corner where the terminal shock and the jet barrel shock interact, a supersonic "jet stream," characteristic of the classic Type IV shock interaction, emanates, as seen in Fig. 7. The jet streams stagnate or impinge on the surface of the model and formed what Warren ${ }^{7}$ called a stagnation circle, giving heat loads greater than the case without injection. As can be seen in Fig. 7 , the "stagnation ring" location on the surface moves radially out with increasing flow rate or jet stagnation pressure. At even higher flow rates, the jet stream is seen to clear the face of the model, thus relieving the dilemma of much higher heating ${ }^{7}$. Also, it is quite noticeable that the pocket of separated flow in the baseline has disappeared with jet injection as a lower pressure is established in the model face.

\section{High Speed Camera Schlieren Data}

For the flowfield with low jet flow rates $\left(\dot{\mathrm{m}}_{\mathrm{j}}=0.05\right.$ and $0.10 \mathrm{lb}_{\mathrm{m}} / \mathrm{sec}$ ) in which the bow shock is no longer discernible, higher speed camera Schlieren was used to better capture the details of the flow structure. The Schlieren images taken with the higher resolution camera, with speeds of up to 1000 frames/sec, are shown in Figs. 8 and 9. Both figures clearly show the dynamics of the process of the supersonic freestream-jet interaction with the sonic and the Mach 2.94 counterflowing jets. For the interaction with the sonic jet, Fig. 8 clearly shows the bow shock to be dispersed, with the jet progressively increasing in length upstream as the flow rate is increased incrementally, remaining essentially like a pencil or aerospike as an LPM jet. The flow sequence is from (a) to (d). The shock is dispersed into striations of compression waves spread over a wide distance such that a shock standoff distance can no longer be defined in the classical sense. With further increase in the flow rate, a critical value is reached at which the compression waves instantaneously coalesce from the LPM to the SPM jet, with the sudden re-emergence of the bow shock and the flow structure described above. The sudden transition from the LPM to SPM jets is quite interesting to observe in the Schlieren video.

The Schlieren images for the interaction between the supersonic freestrean and Mach 2.94 supersonic jet is shown in Fig. 9. The dynamics of the dispersion process of the bow shock is the same as described above. The interaction with the supersonic jet even reveals greater flow details of the shock dispersion into compression waves which are quite visible. Gradually increasing the flow rate resulted in an attendant increase in the length of the LPM jet, with the compression waves being pushed further upstream, becoming so long that part of waves appear truncated from view. Similarly, at the critical
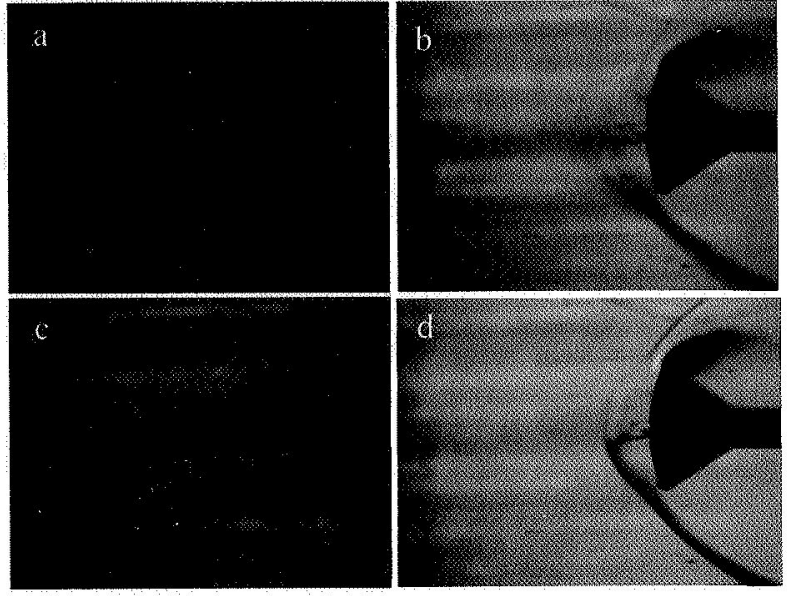

Figure 8. Dispersion of bow shock by counterflowing sonic LPM jet and transition to the SPM jet.
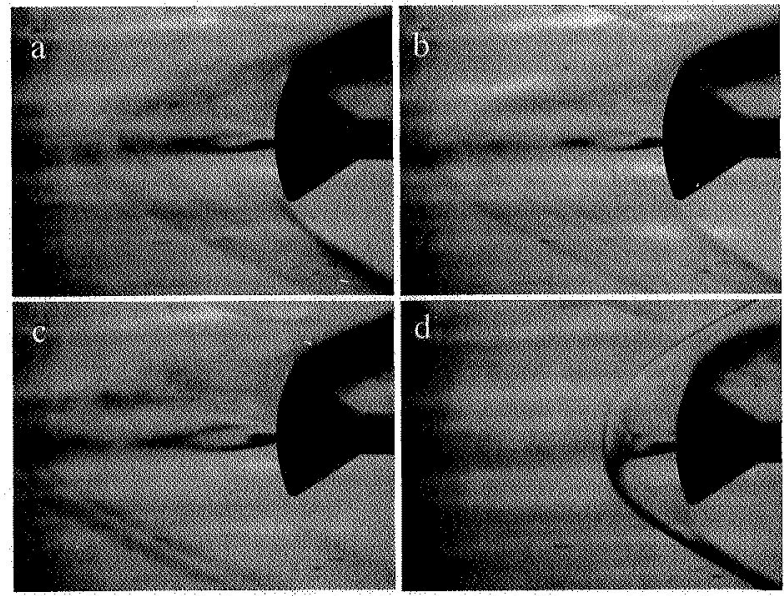

Figure 9. Dispersion of bow shock by counterflowing Mach 2.94 LPM jet and transition to the SPM jet. value of the flow rate, the compression waves suddenly coalesce to form the SPM jet, with the sudden re-establishment of the bow shock with longer standoff distance.

The details of the dynamics of the dispersion of the bow shock as revealed with the aid of the higher speed camera give good insight into the flow physics of the interaction of the freestream and the counterflowing jets. Below the critical flow rate, which was not recorded, the dispersion of the shock wave into compression waves 
suggests three physical processes at play. The first is that the "absence" of the bow shock nullifies the RankineHugoniot jump conditions, resulting in a recovery in total pressure and compression waves that propagate at speeds higher than the speed of sound. This total pressure recovery promotes or induces the second process, that is, a very high rate of mixing of the two opposing streams, with an attendant increase in entropy (mixing, temperature and pressure differences), and becoming a large highly turbulent unsteady shear layer. In the third process, as the flow rate was increased above the critical value, the compression waves, with speeds higher than the velocities near the interface, as discussed above, instantaneously coalesce into a new (spherical) bow shock with a standoff distance greater than that of the baseline, which increased with increasing flow rate.

Another very interesting observation was that the shock dispersion or diffusion process and the sudden transition from the LPM to the SPM interactions seem to repeat in the opposite sense, that is, from the SPM to the LPM also, reproducing the same flow structure. This suggests that the flow phenomena can be "controlled" to have the desired effects in terms of active flow control for thermal management and better aerodynamic performance. This presents two immediate potential technology implications. At supersonic speeds, the shock could be so diffused that the formation of an "N" wave could be mitigated to give either very week or no sonic booms; as long as the jet flow rate is not increased to reestablish strong shocks (Figs. 8 and 9). Also for hypersonic blunt body flows such as for the Apollo capsule and the new Crew Exploration Vehicle (CEV), the entropy layer could be dissipated in the "absence" of the strong bow shock. This could significantly minimize the effects of the attendant ionized flow that wets the vehicle and significantly reduce the radiative heating to the vehicle surface and relieve communication blackout ${ }^{11}$.

The effects of angle of attack are shown in Fig. 10 for the interaction between the Mach 4.0 freestream and the Mach 2.94 counterflowing jet for $\dot{\mathrm{m}}_{\mathrm{j}}=0.10,0.25,0.35$ and $0.50 \mathrm{lb} / \mathrm{sec}$. It is noteworthy that even at the angle of
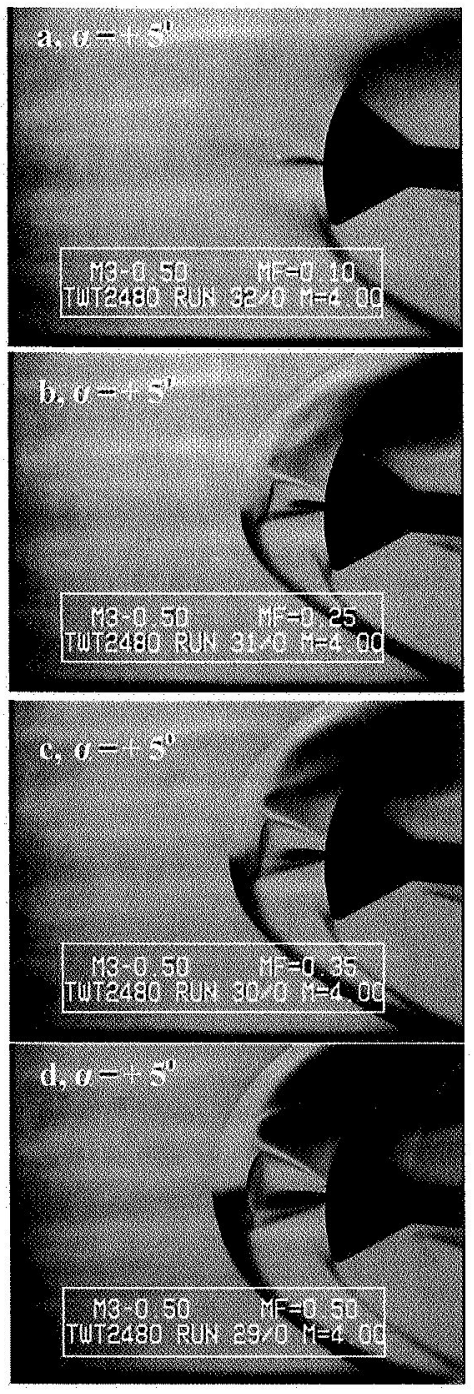
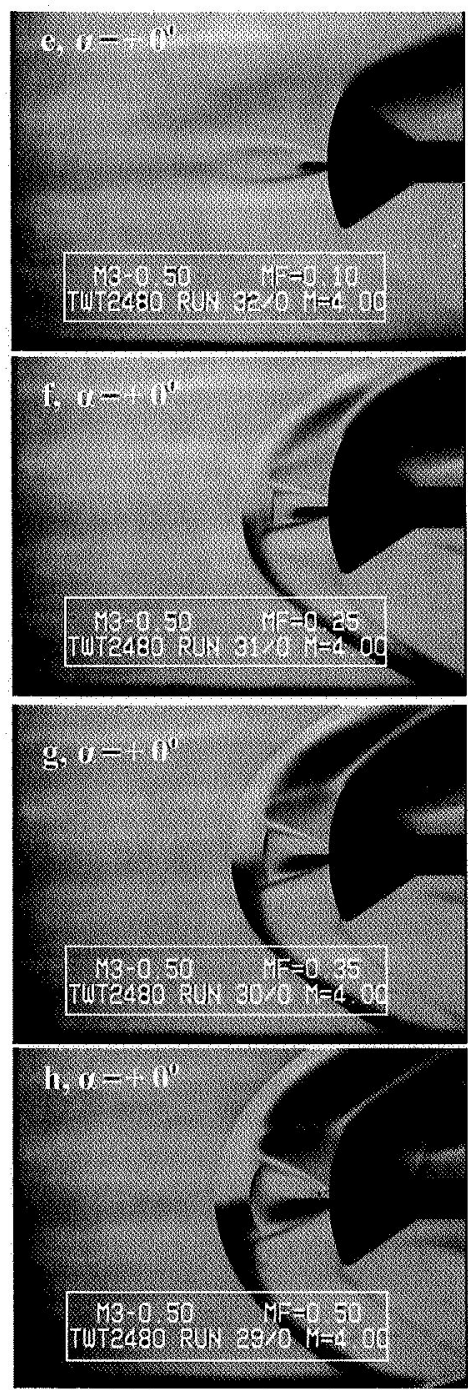
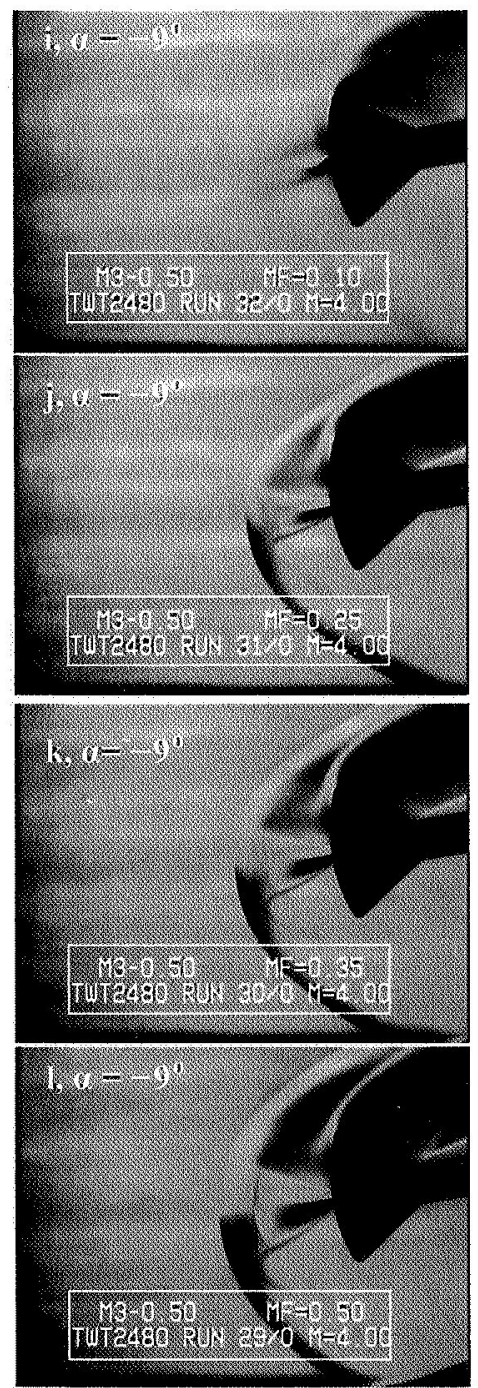

Figure 10. Effects of angle of attack and flow rate on the interaction of the counterflowing iet with Mach 4.00 
attacked of $\alpha=-9^{\circ}$, the flow structure of the LPM jet ( $\dot{\mathrm{m}}_{\mathrm{j}}=0.10 \mathrm{lb} / \mathrm{m} / \mathrm{sec}$ ), is very much sustained in terms of the jet penetration and shock dispersion, though a strong flow asymmetry is introduced as would be expected. This asymmetry does persist and appears to get stronger with increasing flow rate. However, the effects of the angle of attack, at least at small angles, do not seem to severely diminish the potential benefits of the counterflowing jets for active flow control. Also for the $\alpha=0^{\circ}$ cases, Figs $10 \mathrm{e}-\mathrm{h}$, the supersonic jet stream, emanating from the interaction of the jet barrel and terminal shocks no longer impinges on the model.

The heat transfer data from on the face or heatshield of the model for the interaction of the Mach 3.48 and Mach 4.0 freestreams and the 0.5 " diameter nozzles with design Mach numbers of 1.0, 2.44, 2.94 are plotted in Figs. 11 and 12, respectively, and compared with the data for the baseline $\left(\dot{\mathrm{m}}_{\mathrm{j}}=0.0 \mathrm{lb} / \mathrm{sec}\right.$.) at $\alpha=0^{\circ}$. The data is given for each circle or row of heat flux/temperature gauges (Fig. 1c), and each data point on the plot represents the data from each gauge in the row. It is seen that even at $\alpha=0^{\circ}$, the data on a given row are not the same and therefore not coincident. This suggests some asymmetry in the flowfield due to unsteadiness, even with the SPM jets. For both the Mach 3.48 and Mach 4.0 freestreams, Figs. 11 and 12, respectively, consistently show a dramatic decrease
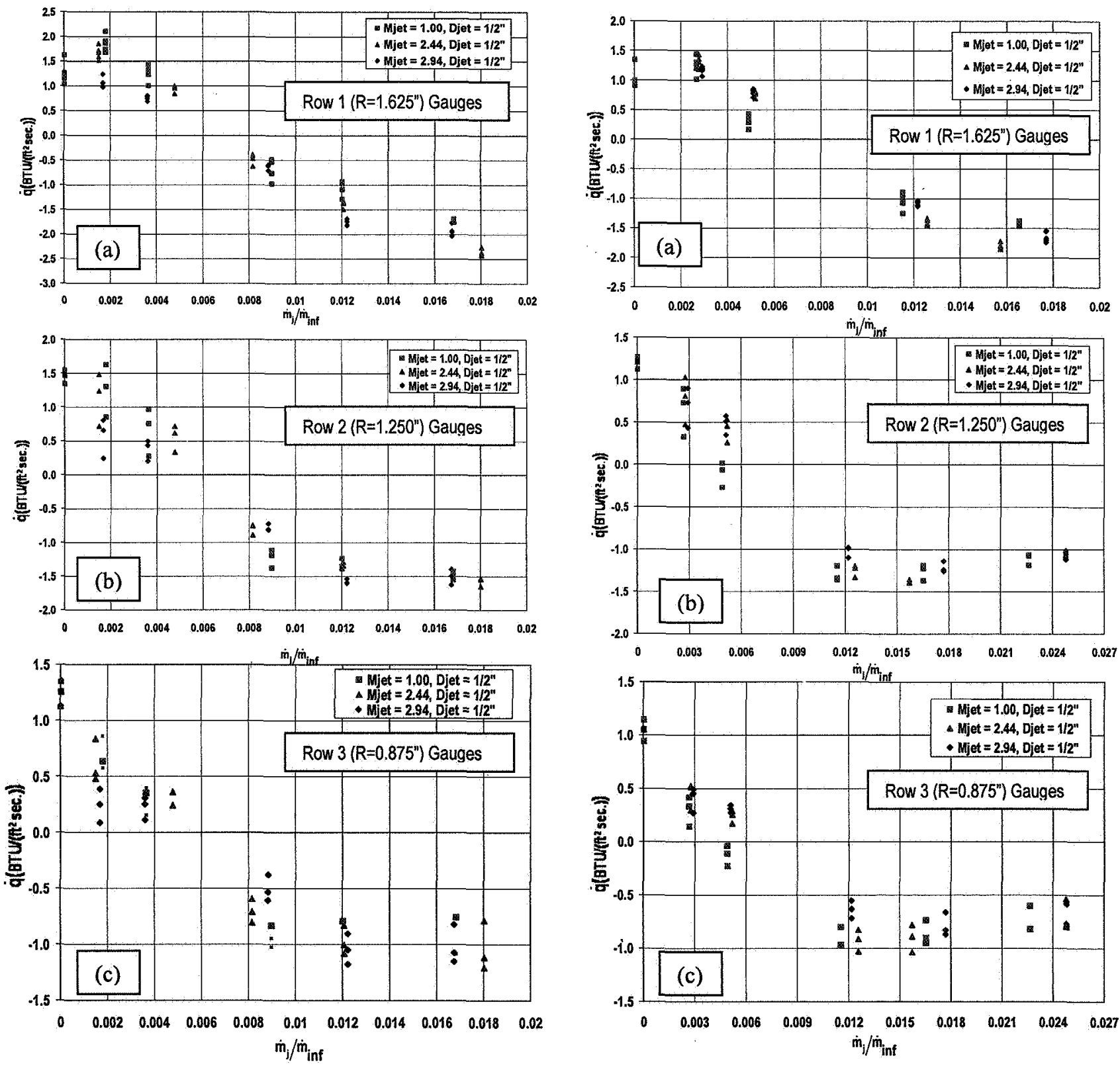

Figure 11. Heat flux vs mass flow, $\mathrm{M}_{\mathrm{inf}}=3.48$

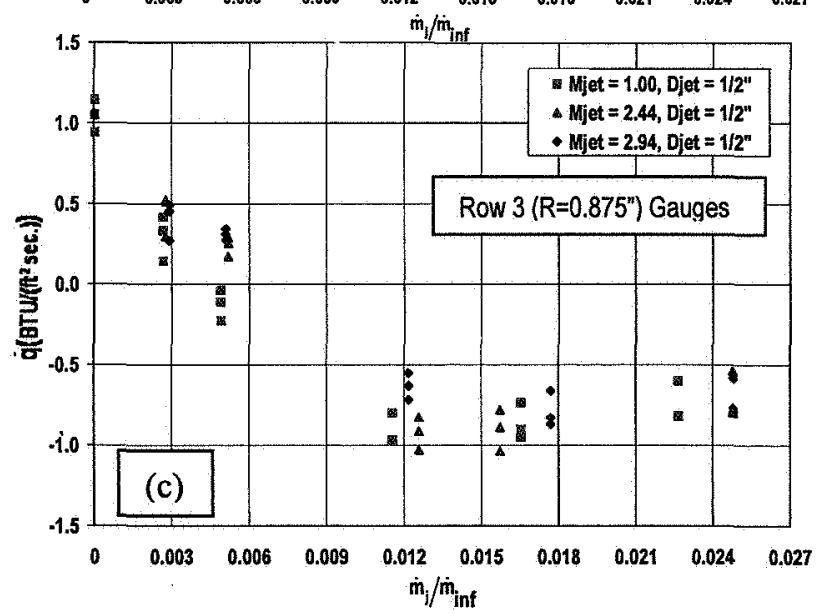

Figure 12. Heat flux vs mass flow, $\mathrm{M}_{\mathrm{inf}}=4.0$ 
in the heat flux compared with that of the baseline for all design jet nozzle exit Mach numbers. However, near the rim of the model (Row 1: $\mathrm{R}=1.625^{\prime \prime}$ ) the data is seen to be higher than the baseline value, with the value for the sonic jet being a little higher than the that of the Mach 2.44 jets for $\dot{\mathrm{m}}_{\mathrm{j}}=0.05$ and $0.10 \mathrm{lb} / \mathrm{m} / \mathrm{sec}$, Figs 11a and 12a. The higher heat flux at low flow rates is consistent with the findings of Grimaud and $M c R e e^{10}$, as well as the results of Stadler and Inouye ${ }^{2}$ who reported an increase in the convective heat transfer of up to $100 \%$ at low counterflowing jet flow rates. This may be that the LPM jet is (nearly) fully-expanded and therefore simply does not have as much cooling effect towards the rim of the model as the under-expanded jets. The decrease in the heat flux shows an almost linear trend with increasing flow rate of the counterflowing jet (Fig.11a), and approaches a minimum value asymptotically (Figs. $11 \mathrm{~b}$ and c). In Fig. 12, a slight upward trend is seen after the minimum is reached. For the under-expanded SPM jets, $\dot{\mathrm{m}}_{\mathrm{j}} \geq 0.25 \mathrm{lb}_{\mathrm{m}} / \mathrm{sec}$., the heat flux is negative, indicating that the flow wetting the model face or forebody cooled the model instead of the shock-induced heating that the model would otherwise experience. Since the heat flux gauges were not calibrated for negative heat flux, the manufacturer was consulted to assess the validity and uncertainty of the data. Medtherm advised that since that the calibration is linear, the negative values were expected to be correct, though the uncertainly could be up to $\pm 10 \%$, instead of about $\pm 3 \%$ for the positive heat flux measurements for which the gauges were calibrated. Such an effect could have a significant application in augmenting the traditional or passive TPS to significantly reduce the risk associated with the harsh aerothermal environment at entry and re-entry into planetary atmospheres.

Figure 13 shows a plot of the shock standoff distance, $\Delta$, normalized by the diameter of the model, versus the flow rates for the 0.5 " diameter nozzles with design exit Mach numbers of 1.0, 2.44 and 2.94 for the Mach 3.48 freestream interactions. The shock standoff distance is seen to increase almost linearly with the jet flow rate, as well as with the design jet nozzle exit Mach number for $\dot{\mathrm{m}}_{\mathrm{j}} \geq 0.25 \mathrm{lb} / \mathrm{sec}$. The trend is the same for the Mach 4.0 freestream. The figure shows a significant increase in the shock standoff distance of about a factor of 4 compared to the case with no jet injection, indicating much weaker shock strength. The broken lines in the figure represent the LPM jets for which the shock standoff distance could no longer be determined because of the severe dispersion or lack of definition of the bow shock.

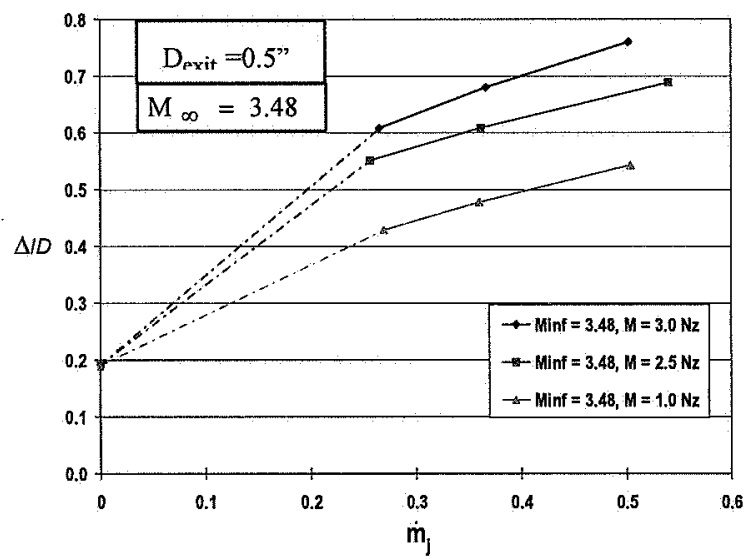

Figure 13. Shock standoff distance vs mass flow.

\section{Numerical Results}

The CFD computations were all pre-test analysis to enable the assessment of some of the key parameters for the run matrix of the wind tunnel tests. As such, some of the test conditions were not exactly the conditions that were used in the pre-test CFD solutions. A large number of pre-test computations were performed, as well. Here we present only the solution for the interaction of the Mach 3.48 freestream and the 0.5 " diameter jet nozzle with design Mach number of 2.94. Figure 14 gives "snapshots" of the computed Mach number, pressure and temperature distributions of this flowfield. In general, there is a good qualitative agreement with the Schlieren images in Figs. 7 and 10 , except for the case with the flow rate, $\dot{\mathrm{m}}_{\mathrm{j}}=0.05 \mathrm{lb} / \mathrm{sec}$., for which the CFD solutions indicate that the stagnation pressure of the jet was not high enough to produce enough jet momentum to establish a LPM or SPM flow structure in the Mach 3.48 freestream. However, for the Mach 4.0 freestream, an LPM jet flowfield was well established with $\dot{\mathrm{m}}_{\mathrm{j}}=0.05 \mathrm{lb}_{\mathrm{m}} / \mathrm{sec}$. because of the slightly lower freestream static pressure.

The LPM jet is quite evident in the figure for $\dot{\mathrm{m}}_{\mathrm{j}}=0.10 \mathrm{lb}_{\mathrm{m}} / \mathrm{sec}$., and it is asymmetric due to the pronounced characteristic unsteadiness and oscillations discussed above. As the flow rate increased, the structure of the flowfield changed to the SPM jet, showing a clear difference from the LPM to the SPM. The CFD solutions also show the SPM flow structure to be much steadier, though with some degree of asymmetry, as pointed out above, consistent with the Schlieren data. The pre-test analysis enabled us to determine the flow rates that would give an LPM jet for the test, as validated by the test results. Computations were also performed for the isolated supersonic jet nozzles to determine the quality of the nozzle design. 

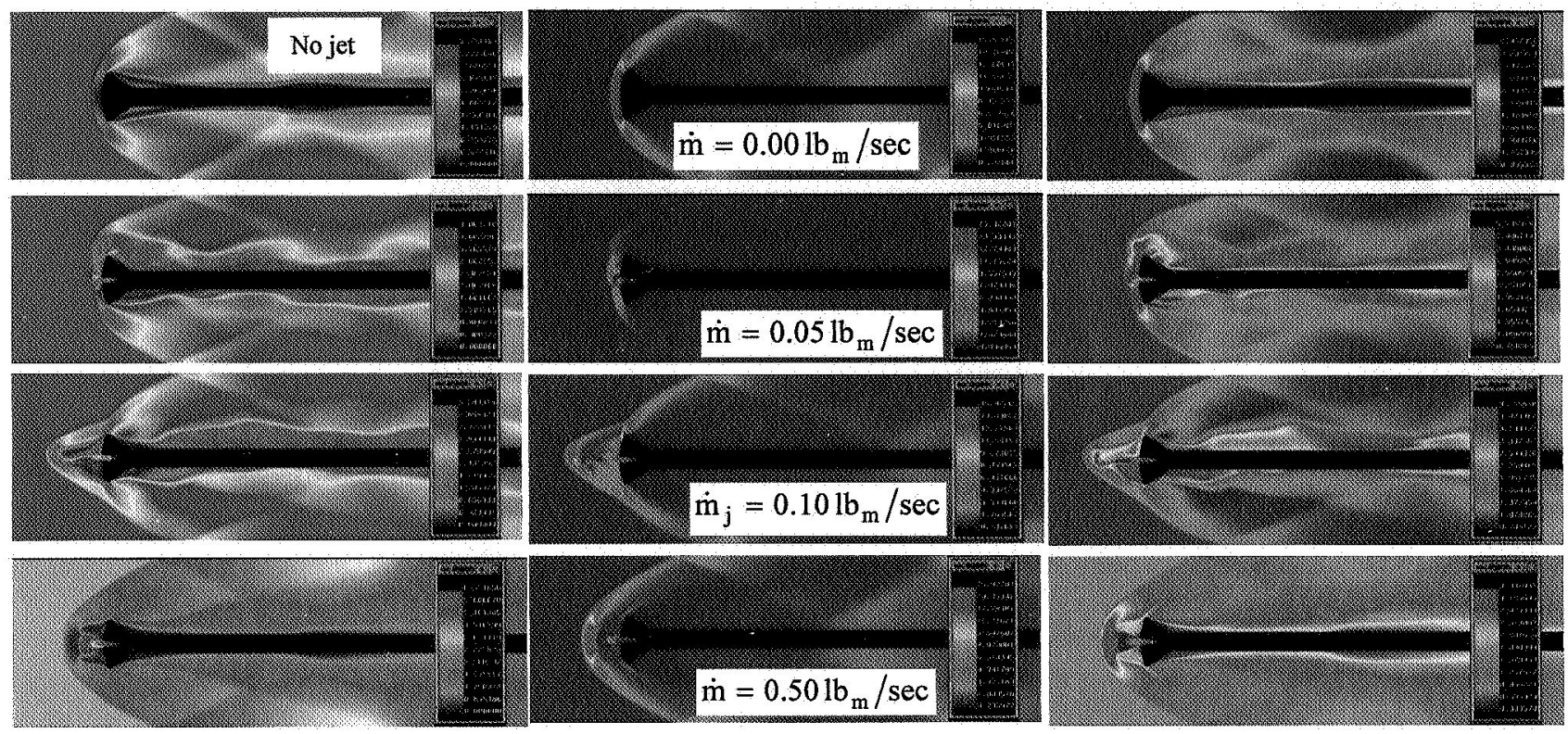

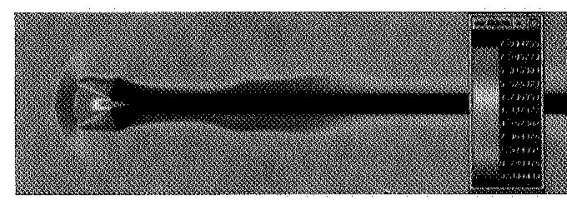

Mach number distributions

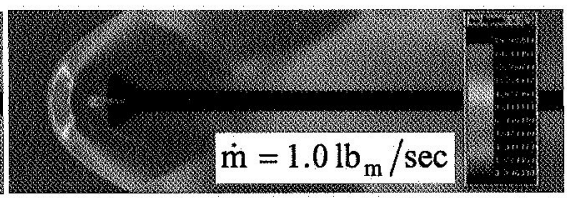

Pressure Distributions

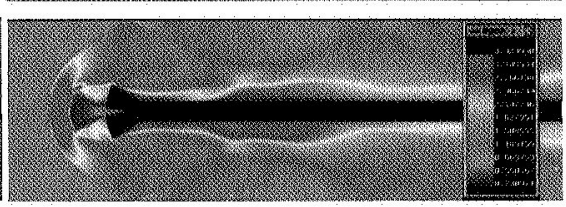

Temperature distributions

Figure 14. Prediction of the flow structure of the interaction of a Mach 3.48 freestream and Mach 2.94 counterflowing jet at different flow rates.

Figure 15 shows the isolated nozzle solution with a design exit Mach number of 2.94 . The CFD solution predicted an exit Mach number of 2.925 , giving just a $0.51 \%$ difference. Figures 16 and 17 show the plots of the reduction in the predicted drag and integrated heat flux on the model for the different flow rates. Figure 16 shows a significant reduction in drag of better than $50 \%$, depending on the flow rate, which is generally consistent with the reductions reported in the literature. Figure 17 is the plot of the percentage change in the integrated heat flux for the model for the same nozzle in the Mach 3.48 freestream flowfield. At low jet flow rates, the heat flux is seen to fluctuate widely because of the unsteadiness and oscillations, with spikes that are considerable larger than the baseline value. However, for the SPM jets with flow rates of $\dot{\mathrm{m}}_{\mathrm{j}}=0.5$ and $1.0 \mathrm{lb} / \mathrm{sec}$, the CFD solution also predicts negative heat flux, and thus consistent with the experimental data, with a percentage reduction of about 500 .

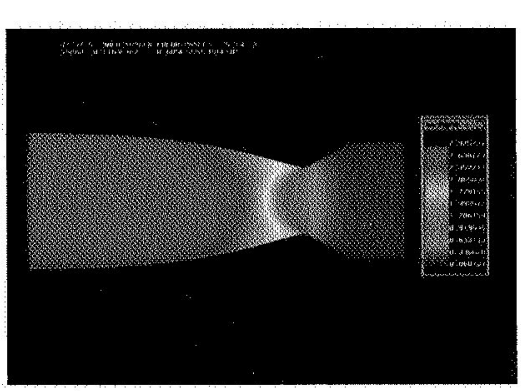

Figure 15. Mach number distribution of 0.5 " exit diameter jet nozzle with design Mach number of 2.94 .

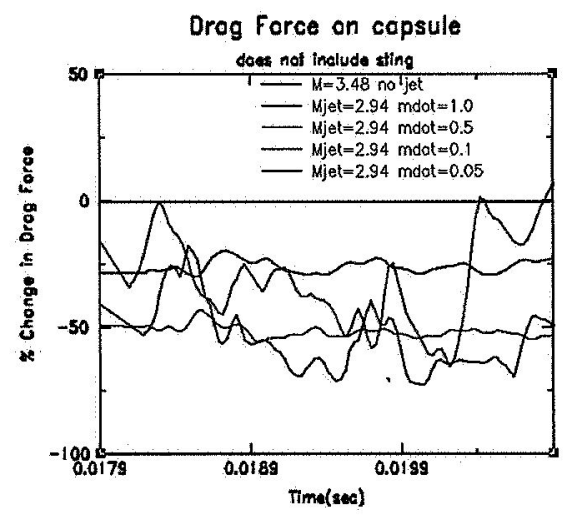

Figure 16. Change in drag with time.

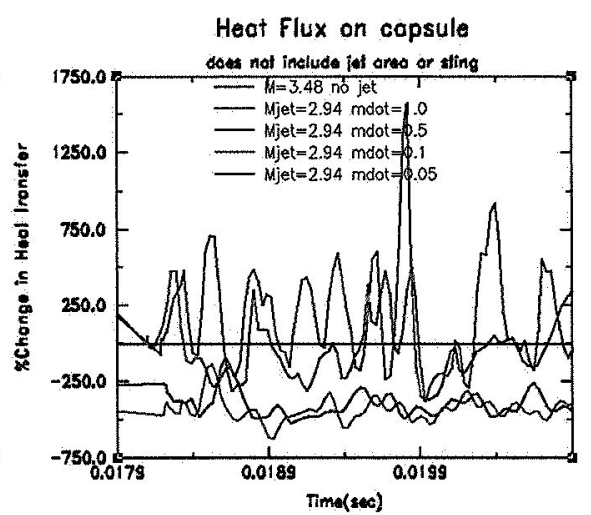

Figure 17. Change in heat flux with time. 
Figure 18 shows a qualitative comparison of the CFD prediction and the Schlieren data of the interaction of the Mach 3.48 freestream and Mach 2.94 jet with a flow rate of $0.5 \mathrm{lb}_{\mathrm{m}} / \mathrm{sec}$. The comparison shows excellent qualitative agreement.

\section{Summary}

Experiments and computational analyses have been performed to investigate the potential benefits of an innovative active flow control concept using counterflowing jets to modify the external flowfields and strongly weaken or disperse the shock waves about spacecraft in supersonic and hypersonic vehicles to significantly reduce aerothermal loads and wave drag. The test model was a $2.6 \%$ Apollo capsule, designed with interchangeable counterflowing jet nozzle inserts. Five axisymmetric nozzles: three sonic and two supersonic with design Mach numbers of 2.44 and 2.94, and exit diameters of 0.25 ", 0.375 " and 0.5 " and flow rates of $0.05,0.10,0.25,0.35$ and $0.50 \mathrm{lb}_{\mathrm{m}} / \mathrm{sec}$ were used in two supersonic freestreams of Mach 3.48 and 4.0. The tests were run at three angles of attack of $+5^{\circ}, 0^{\circ}$ and $-9^{\circ}$. Pre-test CFD analyses were conducted to assess the critical parameters of the freestream-counterflowing interactions. A Schlieren system was used to visualize the flowfield and capture the resulting flow structure and shock interactions.

As seen from the Schlieren data, at low jet flow rates of 0.05 and $0.11 b_{\mathrm{m}} / \mathrm{sec}$, the interactions gave a long penetration mode jet, while the short penetration mode jet was observed at flow rates greater than $0.11 \mathrm{~b}_{\mathrm{m}} / \mathrm{sec}$. The LPM and SPM flow structures are, qualitatively, very consistent with the pre-test CFD solutions. In the LPM, the jet is seen to be (nearly) fully-expanded, resulting in an interaction in which the bow shock is seen to be highly diffused or dispersed into striations of isolated compression waves as shown in the higher speed camera Schlieren data, with the flow structure being very unsteady and oscillatory. The degree of the dispersion of the shock could have several practical implications, such as sonic boom mitigation, improvement in aerodynamic performance (L/D), and the mitigation of the entropy layer in hypersonic blunt body flows. In terms of heat transfer, the results also show significant reductions in heat flux, even giving negative heat flux for most of the SPM interactions, which could be quite significant for TPS development of spacecraft in planetary atmospheric entry and re-entry.

\section{Conclusions}

These findings strongly suggest that the application of counterflowing jets for active flow control could have a strong impact on supersonic and hypersonic vehicle design and performance such as augmenting passive thermal protection systems to significantly reduce the high risk associated with planetary atmospheric entry and re-entry. As a "retrorocket," the CFD analysis also showed that at high flow rates, the concept can be used to decelerate entry and re-entry vehicles and spacecraft, as has also been report in previous work.

A goal of this work was to advance the state-of-the-art in terms of the technology readiness level of the application of counterflowing jets as a viable active control technology. Based on the new findings from the tests and CFD analysis, it is believed that this goal has been achieved.

\section{Acknowledgement}

The first author sincerely thanks Mr. Vernotto McMillan, Manager of Innovative Partnership Program Office at Marshal Space Flight Center for providing the funds that enabled this study to be performed. The first and second authors are also very grateful to Mr. Robert Williams, Ms. Rebecca Farr, Mr. Richard Norman and Mr. Henry Brewster, and others at the Experimental Fluids and Environmental Test Branch for their invaluable support for the planning and conduct of the tests. Your persistence and encouragement are deeply appreciated. Drs. Wang and Daso also express their sincere gratitude to Mr. Joe Ruff of the Thermal and Combustion Analysis Branch for generating the counterflowing jet nozzle contours using the ADAPT code. 


\begin{tabular}{|c|c|c|c|c|c|c|}
\hline \multicolumn{7}{|c|}{ Nozzle Conditions } \\
\hline Design $M_{\text {exit }}$ & $\dot{\mathrm{m}}_{\mathrm{j}}\left(\mathrm{lb}_{\mathrm{m}} / \mathrm{s}\right)$ & $\mathrm{T}_{\mathrm{S}}\left({ }^{\mathrm{O}} \mathrm{F}\right)$ & $P_{S}(p s i)$ & $P_{0}(p s i)$ & $\mathrm{T}_{0}\left({ }^{0} \mathrm{R}\right)$ & Nozzle diameter (inch) \\
\hline \multirow[t]{4}{*}{1} & 0.05 & 34.0 & 85.2 & 86.7 & 496 & 0.250 \\
\hline & 0.10 & 23.5 & 136.7 & 139.1 & 485 & \\
\hline & 0.35 & 17.1 & 431.5 & 439.5 & 479 & \\
\hline & 0.50 & 21.5 & 597.2 & 608.6 & 484 & \\
\hline \multirow[t]{5}{*}{1} & 0.05 & 30.2 & 66.5 & 68.4 & 494 & 0.375 \\
\hline & 0.10 & 23.5 & 94.7 & 97.4 & 487 & \\
\hline & 0.25 & 16.6 & 238.0 & 245.5 & 480 & \\
\hline & 0.35 & 18.7 & 311.3 & 321.4 & 483 & \\
\hline & 0.50 & 12.3 & 446.2 & 460.9 & 476 & \\
\hline \multirow[t]{5}{*}{1} & 0.05 & 29.8 & 56.3 & 57.9 & 493 & 0.500 \\
\hline & 0.10 & 23.1 & 100.2 & 103.2 & 487 & \\
\hline & 0.25 & 9.6 & 232.5 & 239.9 & 473 & \\
\hline & 0.35 & 11.2 & 317.2 & 327.6 & 475 & \\
\hline & 0.50 & 14.8 & 428.6 & 443.1 & 479 & \\
\hline \multirow[t]{5}{*}{2.44} & 0.05 & 34.9 & 46.1 & 47.2 & 498 & 0.500 \\
\hline & 0.10 & 28.9 & 142.8 & 146.5 & 492 & \\
\hline & 0.25 & 19.6 & 235.1 & 241.6 & 483 & \\
\hline & 0.35 & 20.9 & 343.6 & 353.3 & 484 & \\
\hline & 0.50 & 24.6 & 507.7 & 522.5 & 488 & \\
\hline \multirow[t]{5}{*}{2.94} & 0.05 & 50.3 & 62.2 & 63.3 & 512 & 0.500 \\
\hline & 0.10 & 38.2 & 131.1 & 133.4 & 500 & \\
\hline & 0.25 & 21.7 & 310.3 & 316.1 & 484 & \\
\hline & 0.35 & 25.1 & 429.2 & 437.2 & 487 & \\
\hline & 0.50 & 25.1 & 579.7 & 590.8 & 487 & \\
\hline
\end{tabular}

Table 1. Counterflowing nozzle jet flow conditions. 


\section{References}

1. Lopatoff, M., "Wing-Flow Study of Pressure-Drag Reduction at Transonic Speed by Projecting a Jet of Air from the Nose of a Prolate Spheroid of Fineness Ratio of 6," Journal of Spacecraft," NACA RM L51E09, October 1951.

2. Stadler, J.R. and Inouye, M., "A Method of Reducing Heat Transfer to Blunt Bodies by Air Injection," NACA RM A56B27a, May, 1956.

3. Rashis, B., "Preliminary Indications of the Cooling Achieved by Injecting Water Upstream from the Stagnation Point of Hemispherical, $80^{\circ}$ Conical, and Flat-Faced Nose Shapes at a Stagnation Temperature of $4000^{\circ} \mathrm{F}$," NACA RM L57103, $10 / 57$.

4. Ferri, A. and Bloom, M.H., "Cooling by Jets Directed Upstream in Hypersonic Flow," WADC Technical Note 56-382, Sept. 1957.

5. Resler Jr., E.L. and Sears, W.R., "The Prospects for Magneto-Aerodynamics, Journal of the Aeronautical Sciences, Vol. 25, April 1958, pp. 235-245.

6. Ziemer, R.W., "Experimental Investigation of Magnetoaerodynamics," American Rocket Society Journal, Vol. 19, Sept. 1959, pp. 642-646.

7. Warren, C.H.E., "An Experimental Investigation of the Effect of Ejecting a Coolant Gas at the Nose of a Bluff Body," Journal of Fluid Mechanics, Vol. 2, No. 8, 1960, pp 400-417.

8. Charczenco, N. and Hennessey, K. W., "Investigation of a Retro-Rocket Exhausting from the Nose of a Blunt Body into a Supersonic Free Stream," NASA TND-751, 1961.

9. Romeo, D.J. and Sterrett, J.R., "Exploratory Investigation of the Effect of a Forward-Facing Jet on the Bow Shock of a Blunt Body in a Mach 6 Free Stream," NASA TN D-1605, 1963.

10. Grimaud, J.E. and McRee, L.C., "Experimental Data on Stagnation-Point Gas Injection Cooling on Hemispherical-Cone in a Hypersonic Arc Tunnel," NASA TM X-983, July 1964.

11. Beckwith, I.E. and Bushnell, D.M., "Effect of Intermittent Water Injection on Aerodynamic Heating of a Sphere-Cone at Flight Velocities to 18000 Feet per Second," NASA TM X-1128, 1965.

12. Romeo, D.J. and Sterrett, J.R., "Flowfield for Sonic Jet Exhausting Counter to Hypersonic Mainstream," AIAA Journal, Vol. 3, No. 3, 1965, pp. 544-546.

13. Barber, E.A., "Experimental Investigation of Stagnation Point Injection," Journal of Spacecraft and Rockets, Vol. 2, No. 5, 1965, pp. 770-774.

14. Finley, P.J., "The Flow of a Jet from a Body Opposing a Supersonic Free Stream," Journal of Fluid Mechanics, Vol. 26, Part 2, 1966, pp. 337-368.

15. Keyes, J.W. and Hefner, J.N., "Effects of Forward-Facing Jets on Aerodynamic Characteristics of Blunt Configuration at Mach 6," Journal of Spacecraft, Vol. 4, No. 4, April 1967, pp 533-534.

16. Bushnell, D.M. and Huffman, J.K., "Forward Penetration of Liquid Water and Liquid Nitrogen from the Orifice at the Stagnation Point of a Hemispherically Blunted Body in Hypersonic Flow," NASA TM X-1493, March 1968.

17. Jarvinen, P.O. and Adams R.H., "The Effects of Retrorockets on the Aerodynamic Characteristics of Conical Aeroshell Planetary Entry Vehicles," AIAA Paper 70-219, January 1970.

18. McGhee, R.J., "Effects of a Retrorockets Located at the Apex of a $140^{\circ}$ Blunt Cone at Mach Numbers of 3.00, 4.50 and 6.00," NASA TN D-6002, January 1971.

19. Grenich, A.F. and Woods, W.C., "Flow Field Investigation of Atmospheric Braking for High Drag Vehicles with Facing Jets," AIAA-81-0293, January 1981.

20. Workshop on Weakly Ionized Gases Proceedings, Vols. 1 and 2, USAF Academy, Colorado, June 9-13, 1997.

21. Mishin, G.I. "Experimental Investigation of the Flight of a Sphere in Weakly Ionized Air," AIAA 97-2298, June 1997.

22. Ghaniev, Yu.CH., Gordeev, V.P., Krasilnikov, A.V., Lagutin, V.I. and Otmennikov, V.N., "Experimental Study of the Possibility of Reducing Aerodynamic Drag by Employing Plasma Injection," $3^{\text {rd }}$ International Congress on Experimental Fluid Mechanics, Kalingrad, Moscow Region, Russia, June 3-6, 1997.

23. $2^{\text {nd }}$ Weakly Ionized Gases Workshop Proceedings, Norfolk, VA, April 24-25, 1998.

24. $3^{\text {rd }}$ Weakly Ionized Gases Workshop Proceedings, Collocated with the $9^{\text {th }}$ International Space Planes and Hypersonic Systems and Technologies Conference, Norfolk, VA, Nov. 1-5, 1999.

25. Ghaniev, Yu.CH., Gordeev, V.P., Krasilnikov, A.V., Lagutin, V.I., Otmennikov, V.N. and Panasenko, A. V., "Theoretical and Experimental Study of the Possibility of Reducing Aerodynamic Drag by Employing Plasma Injection," AIAA-99-0603, January 1999. 
26. Klimov, A., Leonov, S., Pashina, A., Skvortov, V., Cain, T. and Timofeev, B., "Influence of a Corona Discharge on the Supersonic Drag of an Axisymmetric Body," AIAA 99-4856, Nov. 1999.

27. Chernyi, G.G., "Some Recent Results in Aerodynamic Applications of Flow with Localized Heat Addition," AIAA 99-4819, November 1999.

28. Ganguly B. N., Bletzinger P., and Garscadden, A., "Shock Wave Damping and Dispersion In Nonequilibrium Low Pressure Argon Plasmas," Physics Letters A, Vol. 230, pp. 218-222, 1997.

29. Lowry, H., Stepanek, C., Crosswy, L., Sherrouse, P., Smith, M., Price, L., Ruyten, W., and Felderman, J., "Shock Stucture of a Spherical Projective in Weakly Ionized Air," AIAA 99-0600, Jan. 1999.

30. Lowry, H., Smith, M., Sherrouse, P., Felderman, J., Drakes, J., Bauer, M., Pruitt, D., and Keefer, D., "Ballistic Range Tests in Weakly Ionized Argon," AIAA 99-4822, November 1999.

31. Van Wie, D. M., Wesner, A. L., Gauthier, L. R., "Shock Wave Characteristics Measured in Gas Discharges," ${ }^{\text {rd }}$ AIAA Weakly Ionized Gases Workshop, AIAA 99-4824, November 1999.

32. Kunhardt, E., Saeks, R., Mankowski, J. and Suchomel, C., "One Dimensional Shock Characteristics in Weakly Ionized Gases," AIAA 99-4941, November 1999.

33. Beaulieu, W., Bytyurin, V., Klimov A., Leonov, S., Pashina, A. and Timofeev, B., "Plasma Aerodynamic Wind Tunnel Tests With 1/6 Scale Model of Nose Part of F-15," AIAA 99-4825, November 1999.

34. Malmuth, N.D., Formin, V.M., Maslov, A.A., Fomichev, V.P., Shashkin, A.P., Korotaeva, T.A., Shiplyuk, A.N. and Pozdnyakov, G.A., "Influence of Counterflow Jet on Supersonic Blunt-Body Pressures," AIAA 99-4883, November 1999.

35. Formin, V.M., Maslov, A.A., Malmuth, N.D., Fomichev, V.P., Shashkin, A.P., Korotaeva, T.A., Shiplyuk, A.N. and Pozdnyakov, G.A., "Influence of Counterflow Jet on Supersonic Blunt-Body Pressures," AIAA Journal., Vol. 40, No. 6, June 2002, pp. 1170-1177.

36. Shang, J.S., Hayes, J., Wurtzler, K. and Strang, W., "Jet Spike Bifurcation in High Speed Flows," AIAA Journal, Vol. 39, No. 6, June 2001, pp. 1159-1165.

37. Shang, J.S., Hayes, J. and Menart, J., "Hypersonic Flow over a Blunt Body with Plasma Injection," AIAA 20010344, January 2001.

38. Shang, J.S., Hayes, J., Miller, J. and Menart, J., "Blunt Body in Electromagnetic Hypersonic Flow Field," AIAA 2001-2803, June 2001.

39. Shang, J.S., "Plasma Injection for Hypersonic Blunt-Body Drag Reduction," AIAA Journal, Vol. 40, No. 6, June 2002, pp. 1178-1186.

40. Josyula, E., Pinney, M. and Blake, W., "Applications of a Counterflow Drag Reduction Technique in High Speed Systems," AIAA 2001-2437, June 2001.

41. Gilinsky, M., Washington, C., Blankson, I.M., Shvets,A.I., "Spike-Nosed Bodies and Forward Injected Jets in Supersonic Flow;" AIAA 2002-3918.

42. Daso, E.O., Beaulieu, W., Hager, J.O., "Prediction of Drag Reduction in Supersonic and Hypersonic Flows with Counter-flow Jets", AIAA 2002-5115.

43. Woods, W.C., Jones, K.M. and Genzel, N.N., "Preliminary Investigation of the Effect of Stagnation Point Liquid Injection on the Aerothermodynamics of Blunt Bodies," AIAA 2002-15-2

44. Hayashi, K., Aso, S. and Tani, T., "Numerical Study of Thermal Protection by Opposing Jets," AIAA 2005-188, January 2005.

45. Smith, S.D., "Aerospike Design and Performance Tool - ADAPT Upgrades and Enhancements," Final Report, PT-FR-04-03, Plumetech, Huntsville, AL, June 2004.

46. Chakravarthy, S.R., Szema, K.Y., Haney, J.W., "Unified 'Nose-to-Tail' Computational Method for Hypersonic Vehicle Applications", AIAA Paper No. 88-2564.

47. Ota, D.K., Chakravarthy, S.R., Darling, J.C., "An Equilibrium Air Navier-Stokes Code for Hypersonic Flows", AIAA Paper No. 88-0419, January 1988.

48. Palaniswany, S., Ota, D.K., Charavarthy, S.R., "Some Reacting-Flow Validation Results for USA-Series Codes", AIAA Paper No. 91-0583, January 1991.

49. Pritchett, V.E., Daso, E.O., Wang, T-S., Ota, D. K., Ramakrishna, S.V., "Computational and Experimental Study of Thermal Management of Re-Entry Capsules Using Counterflowing Jets," AIAA 2007-0883, January 2007. 
American Institute of Aeronautics and Astronautics 